\title{
Prevalence of nosocomial infection in Latin American intensive care units
}

\author{
Daniel Curcio \\ on behalf of The Latin American Antibiotic Use in Intensive Care Unit Group ${ }^{\dagger}$
}

doi: 10.3396/ijic.V7i4.039.11

Nosocomial infections (NI) continue to cause significant morbidity, mortality, and added costs in the health care setting. Half of all life-threatening nosocomial bloodstream infections and pneumonias occur in intensive care units (ICU's), despite ICU's representing only 15 to $20 \%$ of all hospital beds. ${ }^{1}$

The primary objective of this study was to obtain prevalence data for $\mathrm{NI}$ from a group of Latin American (LA) mixed ICU's. The participating hospitals were from Argentina $(n=3)$, Bolivia $(n=1)$, Chile $(n=2)$, Colombia $(n=10)$, Costa Rica $(n=1)$, Ecuador $(n=9)$, Perú $(n=5)$ and Venezuela $(n=1)$.

The physicians used a standardized non-commercial website form (http://www.clinicalrec.com; PRIDEH ${ }^{\circledR}$ program) that included all the patients with $\mathrm{NI}$ (demographic data, risk factors for infection due to MDR pathogens [Table I], presence of indwelling devices, type of $\mathrm{NI}$, microbiological documentation and antibiotic treatment of the $\mathrm{NI}$ ).

$\mathrm{NI}$ was defined as an infection arising $\geq 48 \mathrm{~h}$ after admission to hospital that was neither present nor incubating on admission. $\mathrm{NI}$ was confirmed if the patient had signs and symptoms which met the
Centres for Disease Control and Prevention (CDC, Atlanta, GA, USA) definition at the time of survey, or, who had one or more signs or symptoms included in the CDC definition and was being treated with an antimicrobial. $^{2}$

For the analysis, carbapenems, vancomycin, piperacillin-tazobactam, broad-spectrum cephalosporins, tigecycline, polymixins and linezolid were considered as "restricted antibiotics" based on their epidemiological and economical implications in the hospitals.

Results are expressed as proportions. When applicable, two tailed hypothesis testing for difference in proportions was used (Proportion Test); a $p$ value of $<0.05$ was considered significant.

On the day of the survey (October 21, 2010), 32 ICU's participated and recruited 1017 adult patients $(\geq 18 \mathrm{y})$; with a mean length of stay (LOS) from admission of 9.2 days (range: $0-38$ ). Seven hundred and seventyone patients $(72 \%)$ were hospitalized $\geq 48 \mathrm{~h}$.

The prevalence of patients with $\mathrm{NI}$ was $11.6 \%$ (90/771; 95 confidence interval: 9.3-14) (Table II). Patients' median age was 50.5 years (range 13-88); 56

\section{Corresponding author}

Daniel Curcio

Santo Tomé 5239 4to 22 (1419), Capital Federal. Argentina

Email: djcurcio@gmail.com 


\section{Table I. Main risk factors for multidrug-resistant pathogens in hospitalized patients}

Previous antimicrobial therapy in preceding 90 days

Hospitalization for 2 days or more in the preceding 90 days

Invasive procedures (haemodialysis included)

Residence in a nursing home or extended care facility

Inmunosuppression

Previous surgical procedures

Home infusion therapy (including antibiotics)

Modified from American Thoracic Society; Infectious Diseases Society of America. Am I Respir Crit Care Med. 2005; 171:388-416.

were male $(62.2 \%)$. Ninety percent of admission were emergencies (81/90); 52\% (47/90) were surgical; $27 \%$ (24/90) respiratory; $15.5 \%$ (14/90) neurologic; and $5.5 \%$ (5/90) cardiac.

The prevalence of risk factors for infections due to MDR pathogens was $100 \%$. Hospitalization in an acute care hospital for $\geq 2$ days within 90 days; intravenous antibiotic therapy, and immunosuppressive illness or therapy were the commonest risk factors (44\%, 31\% and $18 \%$ respectively). Forty-nine patients (54\%) had 2 - 4 risk factors for infections due to MDR pathogens. $84.5 \%$ of patients were on ventilators (76/90; mean 12.2 days), $91 \%$ (82/90; mean 9.2 days) had urinary catheters, 89\% (80/90; mean 9 days) intravenous catheters; and the prevalence of other invasive devices was 43\% (39/90; mean 10 days). The LOS in ICU from admission to the diagnosis of $\mathrm{NI}$ was 6.3 days (range 3-13).

Of all NIs, 53\% (48/90) were nosocomial pneumonia, 32 of which $(67 \%)$ were ventilator-associated (VAP); 18\% (16/90) were bloodstream infections (BSI), 13\% (12/90) were surgical site infections (SSI), 10\% (9/90) were urinary tract infections (UTI) and 6\% (5/90) others. No patients had $\geq 2$ NIs (Table II).

Eighty-one samples for bacterial culture were obtained from 63 patients $(70 \%)$ before starting antibiotic therapy; $39 \%$ of the samples $(32 / 81)$ were from the respiratory tract (tracheal aspirate [33\%], bronchoalveolar lavage (BAL) [1.2\%], and mini-BAL
[4.8\%]), whereas $37 \%(30 / 81)$ and; $6 \%(5 / 81)$ were from blood and skin or soft tissue respectively.

Thirteen samples (16\%) yielded no pathogens and for 8 $(10 \%)$ the results were pending at the time of the study, leaving 60 (74\%) from which a pathogen had been isolated $(81 \%$ of respiratory tract samples and $67 \%$ of blood cultures) (Table II). The commonest pathogens were extended-spectrum b-lactamase producing (ESBL) enterobacteriaceae (Klebsiella pneumoniae and Escherichia coli) (30\%); Acinetobacter spp. (22\%), meticillin-resistant Staphylococcus aureus (MRSA) (17\%), and Pseudomonas aeruginosa (16\%). Fifty-one percent of the Acinetobacter spp. and 32\% of the Pseudomonas aeruginosa, were resistant to carbapenems (Table II).

Eighty-three percent of the patients with $\mathrm{NI}(75 / 90)$ received "restricted antibiotics", $(\geq 3$ days of treatment in $64 / 75$ patients [ $85.3 \%$ ], and $<3$ days of treatment in $11 / 75$ patients [14.7\%]).

Carbapenems were the most frequently prescribed antibiotics (33/90, 36.6\%), followed by broadspectrum cephalosporins (mainly cefepime) (20/90, $22.2 \%)$, vancomycin $(18 / 90,20 \%)$ and piperacillin/ tazobactam (9/90, 10\%) (Table II). In 50\% of the cases (45/90) a combination of at least two antibiotics was used.

At the time of the study, the patients had received antibiotic for an average of 6.1 days (range 4-8). 


\section{Table II. General and infection data of patients}

\section{Characteristics}

Value

Number of patients recruited, $\mathrm{n}$

1017

Number of patients hospitalized $\geq 48 \mathrm{~h}, \mathrm{n} /$ total $(\%)$

$771 / 1017(72)$

Number of patients with nosocomial infection, n/total (\%)

90/771 (11.6)

Use of invasive device,

- Urinary catheter, $\mathrm{n} / \mathrm{total}(\%)$

$82 / 90(91)$

- Central venous catheter, $\mathrm{n} /$ total $(\%)$

$80 / 90(89)$

- Mechanical ventilator, $\mathrm{n} / \mathrm{total}(\%)$

- Other, n/total (\%)

Type of nosocomial infection,

- Nosocomial pneumonia, n/total (\%)

- Bloodstream infection, $\mathrm{n} /$ total $(\%)$

- Surgical site infection, $\mathrm{n} /$ total (\%)

- Urinary tract infection, $\mathrm{n} /$ total $(\%)$

- Other; n/total (\%)

Clinical Isolates,

- $\mathrm{n}$ isolates/ $\mathrm{n}$ total positive cultures

ESBL'-producing Enterobacteriaceae, n/total (\%)

Acinetobacter spp.

- carb- $\mathrm{R}^{2}$-Acinetobacter spp.

- carb-S3-Acinetobacter spp.

$\mathrm{MRSA}^{4}$

Pseudomonas aeruginosa, $\mathrm{n} /$ total $(\%)$

- carb-R ${ }^{4}-P$.aeruginosa, $\mathrm{n} /$ total $(\%)$

- carb-S5-P.aeruginosa, n/total (\%)

Other, n/total (\%)

Antibiotic treatment

- Carbapenems (imipenem or meropenem) ${ }^{5}$

- Broad-spectrum cephalosporins $s^{5}$

- Vancomycin ${ }^{5}$

$18 / 90(20)$

- Piperacillin-tazobactam ${ }^{5}$

- Fluoroquinolones

- Ampicillin-sulbactam

- Aminoglycosides ${ }^{5}$

- Others

${ }^{1}$ extended-spectrum B-lactamases (Klebsiella pneumoniae and Escherichia coli)

${ }^{2}$ carbapenems-resistant

${ }^{3}$ carbapenems-susceptible

${ }^{4}$ meticillin-resistant $S$. aureus

${ }^{5}$ alone or in combinations with other antibiotic 
Previously published studies show a wide range of prevalence of $\mathrm{NI}$ in general hospitals (i.e. between $5 \%$ and $20 \%)^{3}$ As would be expected, similar prevalence rates were observed in Latin American ICU's (27\% and $23.2 \%$ in Argentina and Mexico respectively). ${ }^{4,5} \mathrm{We}$ acknowledge that the lower observed rate in our study $(\sim 11 \%)$ might be due to a lower sensitivity of diagnosis of infections made by sometimes insufficiently trained ICPs.

All our patients had at least one risk factor for infection with MDR bacteria; mainly hospitalization for $\geq 2$ days and previous antibiotic treatment within the past 90 days. In addition, we found high device utilisation rates comparable with other recent studies (near $90 \%$ for mechanical ventilation, urinary catheter and central venous catheter use). ${ }^{6}$

Nosocomial pneumonia (mainly ventilator-associated pneumonia), was the commonest infection, accounting for more than half of NI. This is often associated with extrinsic risk factors arising from invasive procedures associated with mechanical ventilators and is considered to have the greatest potential for reduction. Knowledge of this risk allows for infection prevention and control planning for ICUs. Like other authors, 4,5 we found two preventable infections, BSI and SSI were the other principal types of $\mathrm{NI}$ present.

MDR-Gram negatives and MRSA were the commonest microorganisms isolated in our patients (83.5\%). The TEST program also found that the prevalence of carbapenems-resistant $A$. baumannii in the region has increased markedly, along with that of carbapenemresistant strains of $P$. aeruginosa and $K$. pneumoniae. ${ }^{7}$

We observed that "restricted" antibiotics (mainly carbapenems), were prescribed for $\geq 3$ days in near $90 \%$ of infected patients. The rationale of this could be studies suggesting the advantages of starting with "the best and most powerful" antibiotic treatment in terms of favourable clinical outcome. ${ }^{8}$

Our web-based method for collection of one-day point prevalence was implemented successfully. However, our results must be taken with caution. It is difficult to compare ICU's with different case mix of patients and staff education in hospital epidemiology. We hope that the limitations of our current study may generate enthusiasm for prospective studies, with more robust designs, in order to improve our knowledge on $\mathrm{NI}$ in LA ICUs.

\section{${ }^{+}$Latin American Antibiotic Use in Intensive Care Unit Group}

Daniel Curcio ${ }^{1}$, Alejandro Duarte ${ }^{2}$, Carlos Humberto Paz Chávez ${ }^{3}$, Carlos Ibáñez-Guzmán ${ }^{4}$, Daniel Alvarado Cueto $^{5}$, David Yepes ${ }^{6}$, Estuardo Salgado ${ }^{7}$, Fausto Guerrero Toapanta ${ }^{8}$, Fernando Paredes Oña ${ }^{9}$, Francisco Molina Saldarriaga ${ }^{10}$, Franco Montufar Andrade ${ }^{11}$, Freddy Morales Alava ${ }^{12}$, Gleinner Cañarte Bermudez ${ }^{13}$, Juan Salas Villasante ${ }^{14}$, Juan Villalobos Vindas ${ }^{15}$, Juan Carlos Fernández Mercado ${ }^{16}$, José Vergara Centeno ${ }^{17}$, Leonina Ferreira Cabrera ${ }^{18}$, Luis Castillo Bravo ${ }^{19}$, Luis Soto Germani ${ }^{20}$, Martín Carvajal Herrera ${ }^{21}$, Martin Oyanguren ${ }^{22}$, Mijail Játiva ${ }^{23}$, Norma Ruiz Oliveros ${ }^{24}$, Oscar López Acosta ${ }^{25}$, Rafael Thomen ${ }^{26}$, Ray Mendoza Franco ${ }^{27}$, Ruben Camacho Alarcón ${ }^{28}$, Ruben Camargo $^{29}$, Stenio Cevallos ${ }^{30}$, Viviana Romero ${ }^{31}$, Erick Valencia ${ }^{32}$, José Rojas Suarez ${ }^{33}$,

${ }^{1}$ Instituto Sacre Cour, Argentina; ${ }^{2}$ Hospital Regional Río Grande, Argentina; ${ }^{3}$ Hospital Central de la Fuerza Aérea y Clinica San Gabriel, Perú; ${ }^{4}$ Hospital Obrero № 1, Bolivia; ${ }^{5}$ Clínica Madre Bernarda, Colombia; ${ }^{6}$ Clinica CES, Colombia; ${ }^{7}$ Clínica La Merced, Ecuador; ${ }^{8} \mathrm{Hospital}$ Carlos Andrade Marin, Ecuador; ${ }^{9} \mathrm{Hospital}$ de Clínicas Pichincha, Ecuador; ${ }^{10}$ Clínica Universitaria Bolivariana, Colombia; ${ }^{11}$ Hospital Pablo Tobón Uribe, Colombia; ${ }^{12}$ Hospital Oncológico Dr.Julio Villacreses Colmont; Ecuador; ${ }^{13}$ Hospital IEES de Portoviejo, Ecuador; ${ }^{14}$ Hospital Regional Docente de Trujillo, Perú; ${ }^{15}$ Hospital México, Costa Rica; ${ }^{16}$ Gestión Salud $\mathrm{SA}$ and Grupo de Investigacion en Cuidados Intensivos y Obstetricia, Colombia; ${ }^{17} \mathrm{Hospital}$ Luis Vernaza, Ecuador; ${ }^{18}$ Hospital Guillermo Grant Benavente, Chile; ${ }^{19}$ Instituto Enfermedades Neoplasicas, Perú; ${ }^{20}$ Hospital San Pablo De Coquimbo, Chile; ${ }^{21}$ Clínica Medihelp Services, Colombia; ${ }^{22}$ Hospital Nacional Edgardo Rebagliati, Perú; ${ }^{23}$ Hospital Eugenio Espejo, Ecuador; ${ }^{24}$ Hospital Militar de Caracas, Venezuela; ${ }^{25}$ Clínica Martha, Colombia; ${ }^{26}$ Clínica La Asunción, Colombia; ${ }^{27}$ Hospital Consorcio Gestión UCl, Colombia; ${ }^{28} \mathrm{Clínica}$ San Gregorio and Hospital IESS-Manta, Ecuador; ${ }^{29} \mathrm{Clinica}$ General del Norte, Colombia; ${ }^{30} \mathrm{Hospital}$ 
Alcivar, Ecuador; ${ }^{31}$ Hospital Padre Pedro Tardivo, Argentina, ${ }^{32}$ Clínicas Salucoop, Colombia, ${ }^{33}$ Gestión Salud SA and Grupo de Investigacion en Cuidados Intensivos y Obstetricia, Colombia.

\section{Acknowledgements}

Argentina: Juan Herrera Paz (Instituto Sacre Cour); Gerardo Filippa y Eduardo Perrault (Hospital Regional Río Grande); Chile: Javiera Gajardo Arias (Hospital San Pablo De Coquimbo); Colombia: Luis Carlos Julio Narváez (Clínica Madre Bernarda); Jezid Miranda Quintero (Gestión Salud SA and Grupo de Investigacion en Cuidados Intensivos y Obstetricia), Rubén Teherán (Hospital Consorcio Gestión UCI), Ana Lucia Rangel Colmenares, Ernesto Alberto Mendoza Hernandez, Rafael Olarte Ardila (Clinica Universitaria del Norte de Santander), Ecuador: Luis González y Gonzalo Sánchez Sánchez (Hospital Luis Vernaza); Bosco Fabian Mendoza Cedeño, Johanna Macías, Blanchy Macías Romero, Otto Intriago Montesdeoca y Guido Macias García (Hospital Oncológico Dr.Julio Villacreses Colmont); Gustavo Granda (Hospital Eugenio Espejo); Boris Villamagua y Yeimi Herrera (Hospital de Clínicas Pichincha). Perú: Deysi Diaz Seijas (Clínica San Gabriel).

\section{Conflict of interest statement}

No funding of any kind has been received by the authors.

\section{References}

1. Bearman GM, Munro C, Sessler CN, Wenzel RP. Infection control and the prevention of nosocomial infections in the intensive care unit. Semin Respir Crit Care Med 2006; 27: 31024. http://dx.doi.org/10.1055/s-2006-945534

2. Centres for Disease Control and Prevention. National nosocomial infection surveillance system manual. Atlanta: CDC; 1999.

3. Ider BE, Clements A, Adams J, Whitby M, Muugolog T. Prevalence of hospital-acquired infections and antibiotic use in two tertiary Mongolian hospitals. I Hosp Infect 2010; 75: 214-219. http://dx.doi.org/10.1016/j.jhin.2010.01.016

4. Rosenthal VD, Guzman S, Orellano PW. Nosocomial infections in medical-surgical intensive care units in Argentina: attributable mortality and length of stay. Am I Infect Control 2003; 31: 291-295. http://dx.doi.org/10.1067/mic.2003.1

5. Ponce de León-Rosales SP, Molinar-Ramos F, DomínguezCherit G, Rangel-Frausto MS, Vázquez-Ramos VG. Prevalence of infections in intensive care units in Mexico: a multicenter study. Crit Care Med 2000; 28: 1316-1321. http://dx.doi. org/10.1097/00003246-200005000-00010

6. Humphreys $\mathrm{H}$, Newcombe RG, Enstone J, et al. Four country healthcare associated infection prevalence survey 2006: risk factor analysis. J Hosp Infect 2008; 69: 249-257. http://dx.doi. org/10.1016/j.jhin.2008.04.021

7. Ibrahim EH, Sherman G, Ward S, Fraser VJ, Kollef MH. The influence of inadequate antimicrobial treatment of bloodstream infections on patient outcomes in the ICU setting. Chest 2000; 118: 146-155. http://dx.doi.org/10.1378/chest.118.1.146

8. Kollef $\mathrm{MH}$. Inadequate antimicrobial treatment: an important determinant of outcome for hospitalized patients. Clin Infect Dis 2000; 31: S131-S138. http://dx.doi.org/10.1086/314079 